\title{
PERILAKU SOSIAL IBU DAN ANAK ORANGUTAN (Pongo pygmeus) DI PUSAT REHABILITASI SATWA YAYASAN INTERNATIONAL ANIMAL RESCUE INDONESIA (YIARI) KABUPATEN KETAPANG
}

\author{
(Social Behavior Mother And Child Orangutan (Pongo Pygmeus) At The Animals \\ Rehabilitation Center International Animal Rescue Foundation Indonesia (YIARI) Ketapang \\ Regency)
}

\author{
Salihin, Hari Prayogo dan Nurhaida \\ Fakultas Kehutanan Universitas Tanjungpura, Jalan Imam Bonjol Pontianak 78124 \\ Email : jeriko0903@gmail.com
}

\begin{abstract}
Rehabilitation is an effort to restore physical condition or animal behavior, to be returned to natural habitat. The rehabilitation program, with the enrichment of the environment as well as possible with habitat in nature, so that animals are motivated to behave naturally. Orangutan social behavior includes orangutan interactions with other orangutans, orangutans with keepers. The purpose of the research is to examine social behavior, performed by mothers and children of orangutans at YIARI. Observations were made using the Focal Animal Sampling method. The results of the research obtained, the percentage of social behavior of Orangutan Mother, Franky (14.14\%) more active than Monti (11.52\%) and children of Orangutans, Oso (15.80\%), more active than Anggun (12.85\%).
\end{abstract}

Keyword: Orangutan, YIARI, Social Behaviour.

\section{PENDAHULUAN}

Lembaga konservasi YIARI adalah lembaga yang melakukan pencegahan hilangnya habitat dan perdagangan illegal satwa serta pemeliharaan personal dengan beralaskan sebagai pecinta binatang. Salah satu yang dilakukan oleh lembaga konservasi YIARI yaitu rehabilitasi orangutan. Rehabilitasi adalah suatu upaya pemulihan kondisi fisik maupun prilaku satwa hasil sitaan agar dapat dikembalikan kehabitat alaminya. Program rehabilitasi dengan pengayaan lingkungan semirip mungkin dengan habitat di alam agar satwa termotivasi untuk berprilaku alami. Perilaku alami orangutan terutama anak orangutan masih bergantung kepada induknya (Atkinson 1997).

$$
\text { Kaplan dan Rogers (2002) }
$$

menjelaskan bahwa pada suatu areal hutan dengan makanan yang cukup tersedia, seperti halnya di Sumatera, para induk akan berkumpul. Anak-anak mereka akan bermain bersama. Kenyataannya, pada waktu para induk bertemu, anak-anak merekalah yang akan menunjukan minat paling tinggi untuk saling berkenalan, dan akan lari kedepan, mendahului induknya. Para induk tidak sesungguhnya bersahabat dan paling sedikit salah satu diantaranya agak resah mengenai pertemuan itu, anak-anak merekalah yang memaksakan perkenalan. Para betina itu akan duduk 
dalam jarak kira-kira beberapa puluh meter jauhnya, sambil saling melirik dan mencuri pandangan kesamping, sedangkan anak-anak mereka asyik bergumul di tengah-tengah. Perilaku yang dilakukan ibu dan anak orangutan sehari-hari di Yayasan International Animal Rescue Indonesia (YIARI) sampai saat ini masih belum diketahui, oleh sebab itu perlu dilakukan penelitian tentang perilaku sosial ibu dan anak orangutan seperti perilaku sosial (social behavior), bermain (autoplay), dan data penunjang seperti makan disediakan (Provisioned food), jalan (traveling), bergerak pindah (moving), makan sendiri (foraging), istirahat (resting), dan bersarang (nesting).

\section{Tujuan dan Manfaat Penelitian}

Penelitian ini bertujuan untuk mengkaji perilaku sosial yang dilakukan oleh ibu dan anak orangutan di Yayasan International Animal Rescue Indonesia (YIARI) Kabupaten Ketapang.

Manfaat yang diperoleh dari penelitian ini di harapkan dapat diketahui perilaku keseharian ibu dan anak orangutan dan menjadi bahan acuan untuk pengelolaan dan pengawasan upaya penyelamatan dan perlindungan orangutan.

\section{METODE PENELITIAN}

Penelitian ini dilakukan di Pusat Rehabilitasi Satwa Yayasan International Animal Rescue Indonesia (YIARI), Kecamatan Muara Pawan, Kabupaten Ketapang, Desa Sei Awan Kiri, dengan waktu penelitian 4 minggu mulai dari tanggal 28 Juli -01
September 2019 dan dilanjutkan dengan pengolahan data.

Penelitian ini menggunakan metode Focal Animal Sampling yaitu dengan mengikuti individu orangutan (ibu dan anak), mulai dari sarang di pagi hari sampai individu tersebut membuat sarang untuk tidur pada saat menjelang malam. Pencatatan data dilakukan dengan mencatat setiap perilaku individu setiap dua menit. Kategori utama perilaku harian meliputi aktivitas bergerak, makan, istirahat, sosial, dan bersarang. Menurut Altman (1974) metode pencatatan tersebut dimungkinkan karena sifat aktivitas orangutan yang lamban baik dalam pergerakan maupun perilaku lainya.

\section{Cara Kerja}

\section{Pencatatan aktivitas harian}

Pencatatan aktivitas sosial orangutan dimulai dengan mengamati orangutan ibu dan anak. Pengamatan dilakukan mulai pada 07.00-11.45 kemudian istirahat, dilanjutkan pada 13.00-17.45, pengamatan dilakukan pada waktu tersebut dikarnakan mengikut kegiatan animal keeper. Pergerakan aktivitas yang dilakukan orangutan dicatat pada lembar kertas atau Tally sheet yang sudah disediakan dalam penelitian, metode yang digunakan adalah Focal Animal Sampling yaitu dengan mengikuti setiap pergerakan ibu dan anak, aktivitas utama yang diamati adalah aktivitas sosial walau demikian dilakukan juga pengamatan aktivitas lainnya sebagai data penunjang. 
a. Sosial

Meliputi perilaku sosial ibu dan anak orangutan dalam melakukan interaksi, kontak atau hubungan, baik dengan orangutan lainnya maupun dengan manusia seperti: bermain, kontak, menyusui, agresif, dan bersuara.

b. Bermain

Perilaku bermain orangutan meliputi interaksi dengan orangutan lainnya, seperti bergulat bersama temantemanya, dan bermain bersama animal keeper.

\section{Pengumpulan Data}

Pengumpulan data ini terdiri dari data primer dan data sekunder, yaitu :

a. Data primer

Data primer ini dikumpulkan di lokasi penelitian yaitu data dari hasil pengamatan perilaku oranguntan (Pongo pygmaeus) yang didapat di lokasi penelitian.

b. Data sekunder

Data sekunder ini dikumpulkan dari berbagai sumber yang meliputi data tentang keadaan umum lokasi penelitian, dan peta lokasi penelitian.

\section{Analisis data}

\section{a. Analisis kuantitatif}

Pengolahan data yang dilakukan dengan mencatat semua perilaku harian ibu dan anak orangutan selama mereka beraktivitas, perhitungan kemudian dimasukan dalam bentuk tabel dan grafik dan akan diketahui persentase perilaku harian ibu dan anak orangutan di Yayasan International Animal Rescue Indonesia (YIARI) Kecamatan Muara Pawan, Kabupaten Ketapang, Desa Sei
Awan Kiri. Perhitungan persentase perilaku sebagai berikut:

$\%$ Perilaku $=\frac{\text { Jumlah total satu perilaku }}{\text { Jumlah total semua perilaku }} \times 100$

b. Analisis deskriptif

Analisis data dilakukan secara deskriptif dengan menampilkan data dalam bentuk table dan grafik, juga penjelasan mengenai perilaku keseharian ibu dan ank orangutan berdasarkan pengamatan langsung dan studi literatur tentang penelitian orangutan sebelumnya.

\section{HASIL DAN PEMBAHASAN}

Pengamatan yang dilakukan terhadap 4 individu orangutan yang ada di Kawasan Yayasan International Animal Rescue Indonesia yaitu betina dewasa Monti berumur 11 tahun dan Franky 13 tahun, Monti adalah ibu orangutan individu anak betina Anggun yang berumur 2 tahun 5 bulan dan Franky adalah ibu individu anak jantan Oso yang berumur 2 tahun 1 bulan. Monti masuk ke YIARI umur 1 tahun pada tahun 2009, Franky umur 6 tahun pada tahun 2013, Anggun umur 1 tahun pada tahun 2016, sedangkan Oso lahir di YIARI pada tahun 2017.

Orangutan tersebut tinggal di setiap pulau yang berbeda Monti dan Anggun tinggal di Pulau Rangkong yang jauh dari kantor Yayasan, Franky dan Oso tinggal di Pulau Enclouser yang tak jauh dari kantor Yayasan tepat dibelakang kantor pengamatan selama empat minggu dapatlah berbagai perilaku 4 individu orangutan. Masing-masing melakukan berbagai aktivitas harian seperti makan, bersarang, jalan, bermain, aktivitas lain, sosial, interaksi, bersarang 
dan istirahat. Perilaku harian merupakan seluruh perilaku yang dilakukan orangutan dimulai dari bangun tidur pada pagi hari sampai kembali tidur sore atau malam hari. Orangutan yang terdapat di dalam area enclouser hanya orangutan Franky dan Oso itulah mengapa orangutan Franky lebih banyak istirahat dibandingkan beraktivitas (Gambar 1).

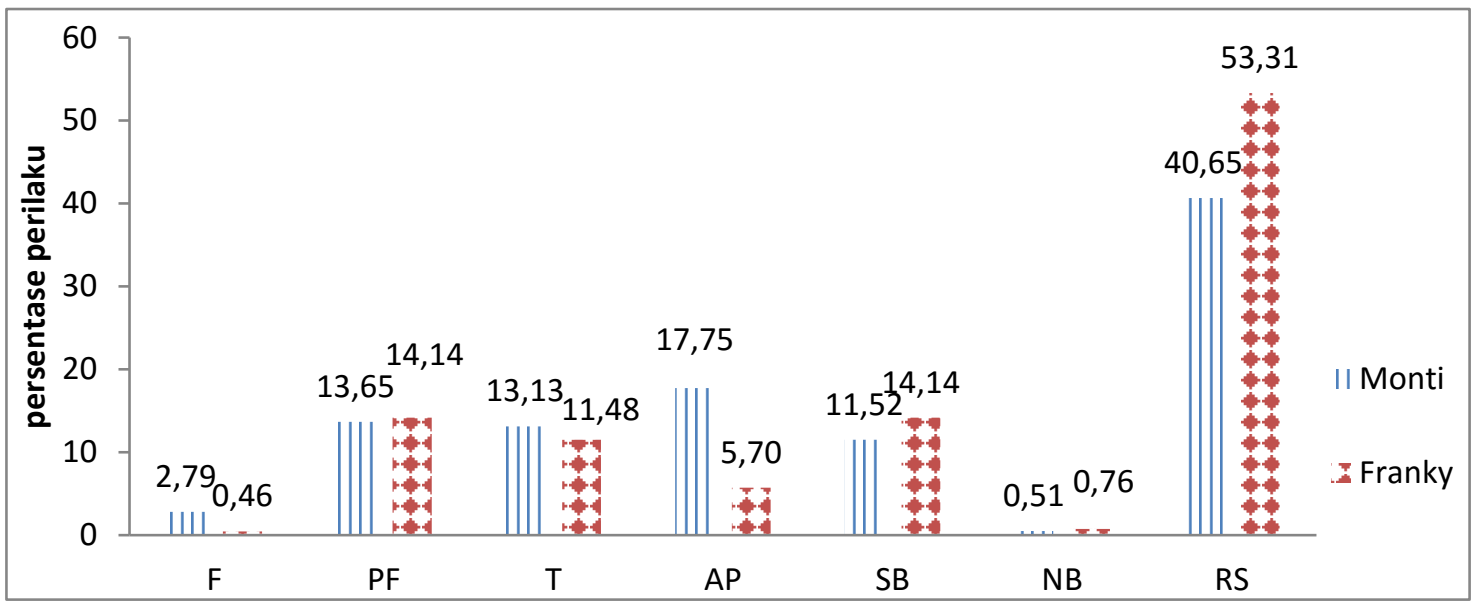

Gambar 1 : Persentase Perilaku Harian Ibu Orangutan (Pongo pygmeus) di Pusat Rehabilitasi Satwa Yayasan International Animal Rescue Indonesia (YIARI) (Percentage of Daily Behaviour Orangutan Mother at Rehabilitation Center International Animal Rescue Foundation Indonesia (YIARI)

Keterangan : $\mathrm{F}=$ makan, $\mathrm{PF}=$ makan disediakan, $\mathrm{V}=$ bersuara, $\mathrm{T}=$ jalan, $\mathrm{AP}=$ bermain, $\mathrm{OTH}=$ aktivitas lain, $\mathrm{SB}=$ sosial, $\mathrm{HI}=$ interaksi dengan manusia, $\mathrm{NB}=$ bersarang, $\mathrm{RS}=$ istirahat $(F=$ food,$P F=$ Provisioned food, $V=$ Vocalizing, $T=$ Travelling, $A P=$ Autoplay, $O T H=$ Other,$S B=$ Social Behaviour, $H I=$ Human Interaction, $N B=$ Nest Building, Rs $=$ Resting).

Secara keseluruhan perilaku ibu orangutan yang bernama Monti lebih aktif daripada ibu Orangutan Franky, hal ini terlihat pada waktu istirahat Orangutan Monti (40,65\%) lebih sedikit bila dibandingkan dengan yang dilakukan Franky (53,31\%). Orangutan Monti lebih sering melakukan aktivitas dibandingkan orangutan Franky dikarenakan orangutan Monti lebih sering mengikuti pergerakan orangutan lainya dan bermain bersama orangutan lainnya. Berbeda dengan Franky yang malas-malasan dan jarang melakukan aktifitas hanya duduk dan tidur di atas pohon. Persentase perilaku harian anak Orangutan yang bernama Anggun dan Oso lebih aktif Anggun dibandingkan dengan Oso hal ini terlihat pada waktu istirahat orangutan Anggun (27,34\%) lebih sedikit di bandingkan dengan orangutan yang bernama Oso $(28,67 \%)$ karena Anggun sering bermain bersama induknya dan orangutan lainnya. Oso tidak ada teman maupun orangutan lain di dalamnya, Oso hanya main sendiri dan sibuk sendiri (Gambar 2). 


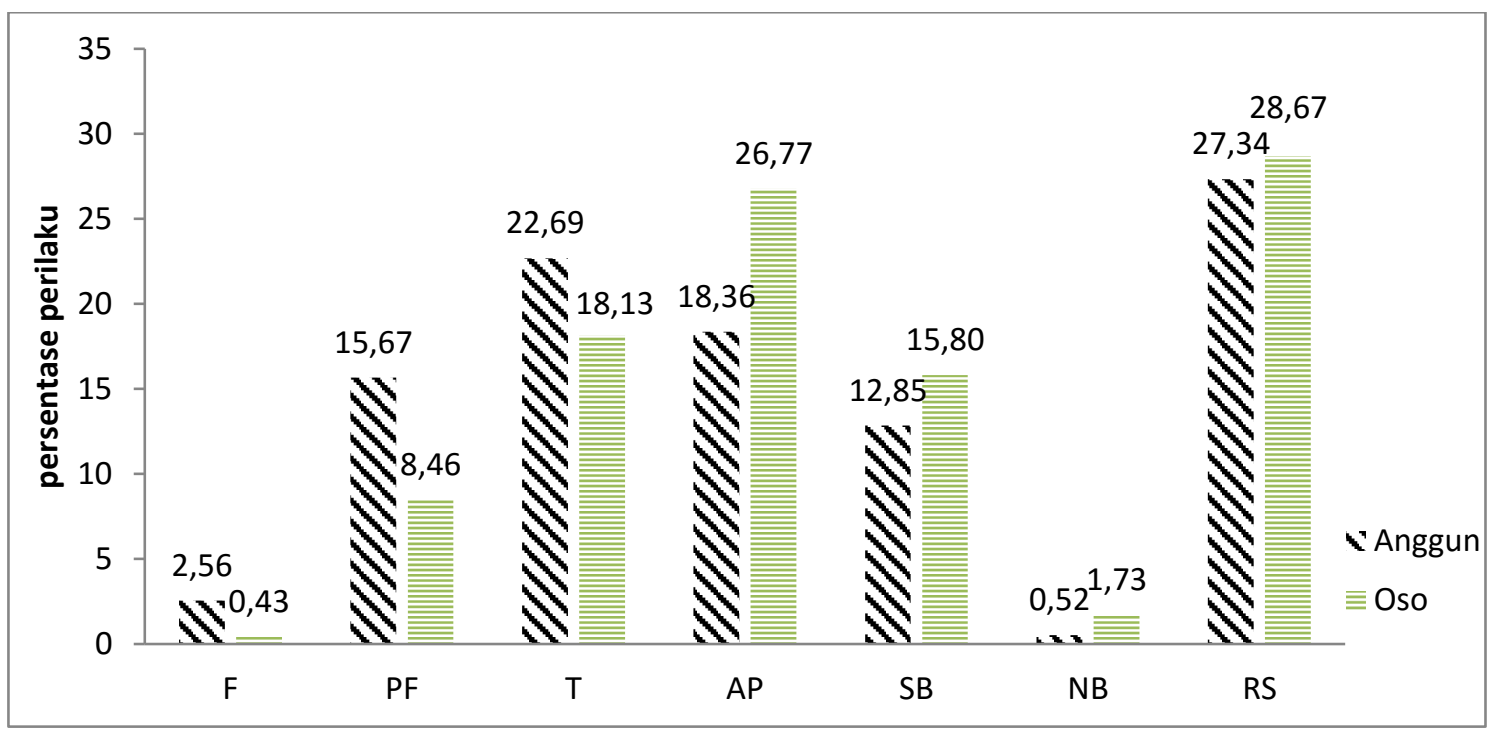

Gambar 2 : Persentase Perilaku harian anak Orangutan (Pongo pygmeus) Rehabilitasi Satwa Yayasan International Animal Rescue Indonesia (YIARI) (Percentage of Daily Behaviour Orangutan child (Pongo pygmeus) at Rehabilitation Center International Animal Rescue Foundation Indonesia (YIARI)

Keterangan : $\mathrm{F}=$ makan, $\mathrm{PF}=$ makan disediakan, $\mathrm{V}=$ bersuara, $\mathrm{T}=$ jalan, $\mathrm{AP}=$ bermain, $\mathrm{OTH}=$ aktivitas lain, $\mathrm{SB}=$ sosial, $\mathrm{HI}=$ interaksi dengan manusia, $\mathrm{NB}=$ bersarang, $\mathrm{RS}=$ istirahat. $((F=$ food,$P F=$ Provisioned food, $V=$ Vocalizing, $T=$ Travelling, $A P=$ Autoplay, $O T H=$ Other,$S B=$ Social Behaviour, $H I=$ Human Interaction, $N B=$ Nest Building,$R s=$ Resting).

\section{Perilaku Sosial}

Perilaku sosial adalah perilaku antara 2 individu orangutan atau lebih. Perilaku sosial merupakan aktivitas orangutan yang meliputi mengikuti (mengikuti orangutan lain atau mendekati orangutan lain/meminta makan), bermain (bermain dengan teman, bermain kasar tapi bukan berkelahi, dan berpelukan), Agresif ( orangutan menunjukan ketakutan, marah, frustasi terhadap orangutan lain dapat ditunjukan dengan melemparkan benda seperti kayu dan lainya), kontak (tanpa main seperti contohnya: merangkul, memeluk, menyentuh, memegang atau beristirahat bersama dengan bersentuhan tanpa bermain).
Perilaku sosial yang dilakukan orangutan yang ada di Yayasan International Animal Rescue Indonesia (YIARI) menunjukan bahwa setiap perilaku individu orangutan berbedabeda yaitu Monti (11,52\%), Anggun $(12,85 \%)$, Franky $(14,14 \%)$ dan Oso $(15,80 \%)$. Franky dan Oso kerap kali melakukan perilaku sosial, bermain dengan cara bergulat berdua diatas pohon dan Franky sering menyusui Oso, perilaku yang sering kali terlihat pada Franky dan Oso adalah perilaku sosial kontak karena Oso sering menempel pada induknya. Berbeda pada Monti dan Anggun yang berinteraksi dengan orangutan lain dan juga biasanya dengan keeper selama pengamatan berlangsung. perilaku sosial terhadap keeper 
cenderung sama yakni saat keeper bertugas memberikan makan, biasanya keeper mengajak berinteraksi terlebih dahulu.

Penelitian yang dilakukan Suhandi et al. (2015) di Kebun Binatang Kasang Kulim Kecamatan Siak Hulu Kabupaten Kampar Riau, perilaku ibu dan anak orangutan Lisa sebagai induk juga sering melakukan kontak sosial dengan anak dengan cara bermain bersama anak dan menyusui anak, namun berbeda dengan Junet yang berinteraksi hanya dengan keeper. Perilaku sosial orangutan dengan sesamanya dapat terlihat ketika Lisa bermain dengan anak, Lisa menyusui anak, Lisa menggendong anak, Manis mengikuti induk, Manis menyusu dengan induk, dan ketika Tina dan Boy saling bergelut. Hasil penelitian yang dilakukan Mawarda (2010) menunjukkan bahwa perilaku sosial ke empat individu orangutan mempunyai nilai yang tidak jauh berbeda. Hal ini dikarenakan orangutan yang ditempatkan dalam kandang terbuka dan tertutup mempunyai perilaku sosial dengan sesame orangutan, dan setiap individu orangutan mempunyai perlakuan yang sama oleh keeper. Perilaku sosial orangutan dengan keeper terjadi pada saat pembersihan kandang tertutup, pemberian pakan dan pada saat keeper memasukkan orangutan dari kandang terbuka ke kandang tertutup, begitu juga pada saat mengeluarkan orangutan dari kandang tertutup ke kandang terbuka.

Perilaku sosial orangutan Monti dan Anggun dengan sesamanya dapat terlihat ketika mereka berkumpul bersama dan beristirahat bersama pada waktu itulah mereka melakukan perilaku sosial bermain, bergulat, dan kontak. Rijksen (1978); Kuncoro (2004) pada pengamatannya terhadap orangutan rehabilitan mengemukakan bahwa kondisi-kondisi sosial pada orangutan rehabilitan adalah merupakan bagian dari adaptasinya untuk mengatasi kondisi yang tidak familiar di hutan. Rijksen (1978) pada pengamatannya terhadap orangutan rehabilitasi mengemukakan bahwa kondisi-kondisi sosial pada orangutan rehabilitas adalah merupakan bagian dari adaptasinya untuk mengatasi kondisi yang tidak familiar di hutan (Gambar 3). 


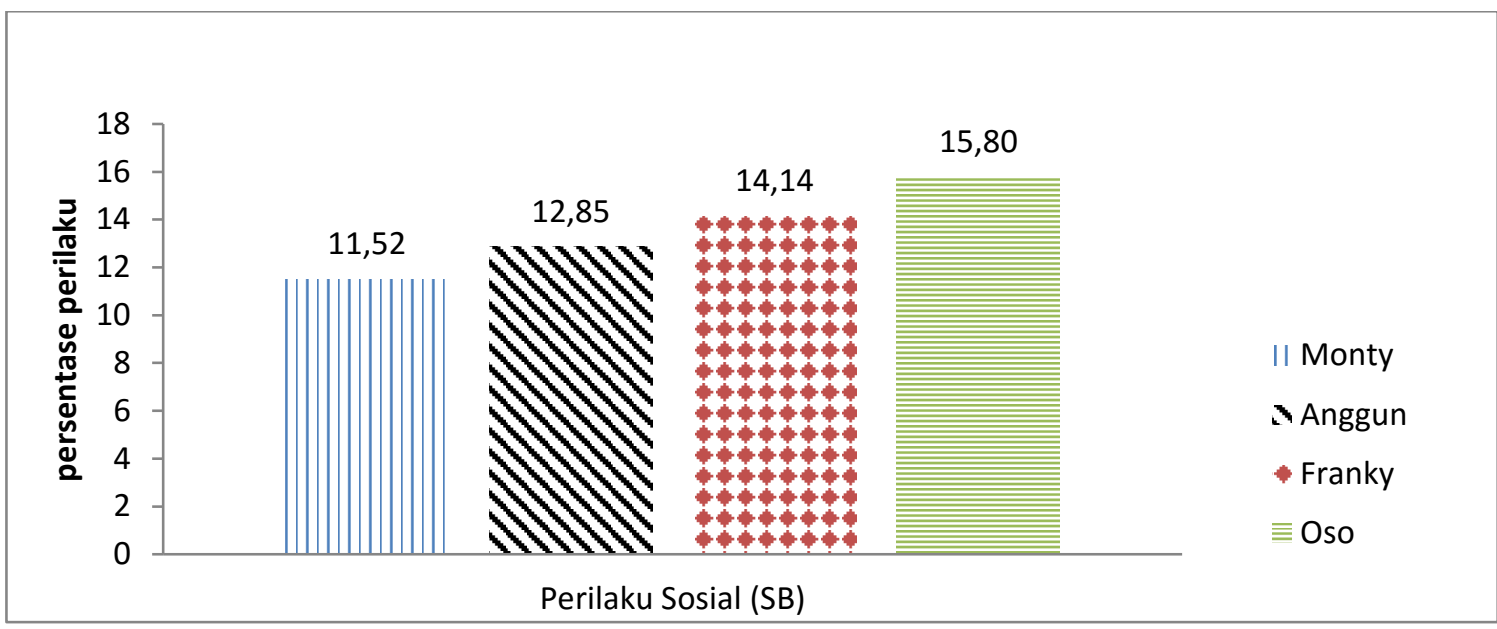

Gambar 3. Persentase Perilaku Sosial untuk Ibu dan Anak Orangutan Yayasan International Animal Rescue Indonesia (YIARI) Kabupaten Ketapang (Percentage of Social Behaviour Mother and Child Orangutan at Rehabilitation Center International Animal Rescue Foundation Indonesia (YIARI)

\section{Perilaku Bermain}

Perilaku bermain orangutan meliputi pergerakan orangutan bermain sendiri dan bemain bersama temantemannya seperti bergulat sering kali

terlihat pada waktu pengamatan adanya interaksi dengan individu lain. Hasil persentase bermain sendiri yang dilakukan oleh Monti, Anggun, Franky dan Oso (Gambar 4).

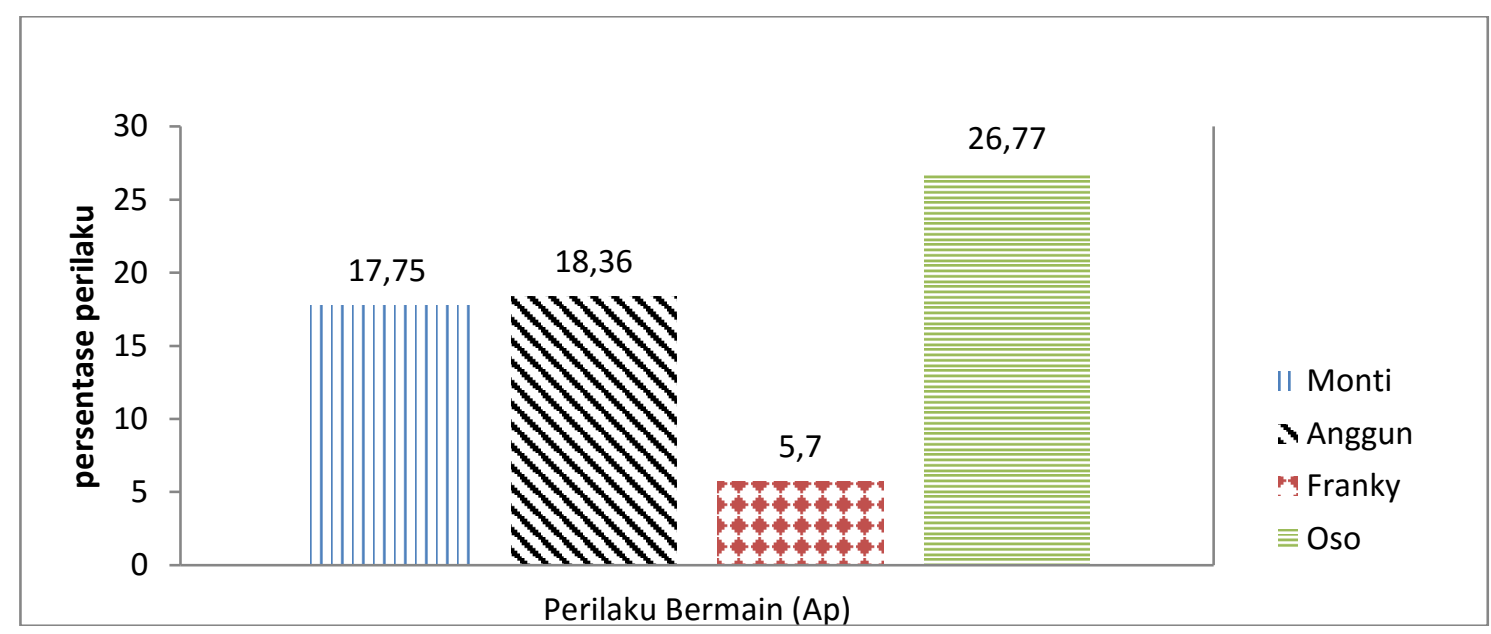

Gambar 4. Persentase Harian Perilaku Bermain untuk Ibu dan Anak Orangutan Yayasan International Animal Rescue Indonesia (YIARI) Kabupaten Ketapang (Percentage Daily of Play Behaviour Mother and Child Orangutan at Rehabilitation Center International Animal Rescue Foundation Indonesia (YIARI)

Monti lebih sering melakukan aktivitas bermain sendiri seperti berguling, mainkan ranting pohon, dan mainkan daun. Sering juga Monti melakukan interaksi bersama orangutan lainnya seperti bergulat, dan saling gigit. 
Monti dibandingkan dengan Franky yang hanya melakukan perilaku sosial bersama anaknya, dan interaksi bersama animal keeper saat masuk ke pulau untuk memberikan makanan. Sebaliknya juga anak orangutan Franky yang bernama Oso lebih aktif bermain sendiri, dan bermain bersama induknya bergulat diatas pohon maupun saling gigit, dibandingkan anak orangutan Monti yang bernama Anggun yang sering bermain bersama-sama orangutan lainnya dan mengikuti pergerakan orangutan lainnya, hal ini dikarenakan pulau yang ditinggali oleh orangutan Monti dan Anggun lebih ramai individu orangutannya, dan sering dimasuki oleh Keeper. Orangutan Monti dan Anggun lebih sering melakukan bergerak dan bermain dibandingkan aktivitas lainnya. Berbeda dengan orangutan Franky dan Oso pulau yang ditinggali lebih sepi hanya ditinggali berdua dan pulaunya lebih kecil, Oso yang sering bermain sendiri dibandingkan dengan induknya.

Penelitian Hermawan et al. (2018) Anak-anak orangutan yang berusia muda banyak melakukan aktivitas bermain. Namun, kedua orangutan tersebut cenderung bermain sendiri karena tidak banyak anak orangutan yang sebaya yang ada di di pusat rehabilitasi Protect Our Borneo POB (POB hanya memelihara dua anak orangutan). Otong dan Oka bermain dengan menggunakan bendabenda di sekitarnya. Hal ini didukung dengan perilaku sosial kedua anak orangutan yang rendah. Perilaku sosial dilakukan dengan perawat. Sedangkan penelitian yang dilakukan
Purnawan et al. (2016) di Yayasan International Animal Rescue Indonesia (YIARI) tingkah laku bermain merupakan tingkah laku yang sering dilakukan oleh kelompok orangutan hampir semua individu melakukan aktivitas bermain, tingkah laku bermain merupakan salah satu pembelajaran bagi orangutan agar dapat memiliki gerak yang cepat yang sama halnya orangutan di alam. Aktivitas bermain semakin menigkat, terutama setelah pemberian pakan.

Berdasarkan hasil pengamatan kelompok ini biasanya pada saat makan juga sering melakukan aktivitas bermain terkadang saling berebut makanan yang dipegang. Selama pengamatan aktivitas sosial dilakukan pada orangutan sasaran, beberapa individu orangutan sasaran ditemukan berada dalam kondisi yang ketat, dimana waktu aktivitasnya dihabiskan dalam kondisi berpasangan dan saling ketergantungan seperti pada joni dan pinoh selalu berkelompok baik dalam mencari makan maupun istirahat.

\section{KESIMPULAN}

Berdasarkan hasil penelitian mengenai Perilaku sosial Ibu dan Anak Orangutan (Pongo pygmeus) di Pusat Rehabilitasi Satwa Yayasan International Animal Rescue Indonesia (YIARI) Kabupaten Ketapang, dapat disimpulkan bahwa:

1. Persentase perilaku sosial induk orangutan dan anak orangutan yang dilakukan, Monti (11,52\%), Franky (14,14\%), Anggun (12,85\%), Oso $(15,80 \%)$. Perilaku bermain Monti 
(17,75\%), Franky (5,70\%), Anggun $(18,36 \%)$, Oso $(26,77 \%)$.

2. Secara keseluruhan perilaku sosial ibu orangutan yang bernama Franky lebih aktif daripada ibu Orangutan Monti terlihat pada waktu karena orangutan Franky lebih banyak menghabiskan waktu berdua dengan anaknya dibandingkan dengan Monti yang asyik bermain berama orangutan lainnya. Sementara itu untuk persentase perilaku sosial anak Orangutan yang bernama Anggun dan Oso, lebih aktif Anggun dibandingkan Oso hal ini karena orangutan Oso lebih banyak menempel pada induknya dibandingkan Anggun yang sering sekali berjauhan dari induknya.

\section{SARAN}

Perencanaan lebih lanjut diperlukan untuk mengantisipasi kondisi-kondisi kritis seperti kekeringan dan minim buah terutama untuk orangutan rehabilitas baru. Penelitian lebih lanjut perlu dilakukan mengenai strategi makan dan pergerakan musiman untuk menilai adaptasi orangutan rehabilitas secara lebih komprehensif, dan perlu dilakukan pengawasan disemua lokasi terutama kawasan yang berbatasan langsung dengan penduduk desa agar tidak terjadinya penebangan liar serta perburuan terhadap orangutan.

\section{UCAPAN TERIMA KASIH}

Peneliti secara khusus mengucapkan terima kasih yang sebesar-besarnya kepada semua pihak yang telah membantu. Peneliti banyak menerima bimbingan, petunjuk dan bantuan serta dorongan dari berbagai pihak baik yang bersifat moral maupun material. Peneliti mengucapkan terimakasih sebesarbesarnya kepada Yayasan International Animal Rescue Indonesia (YIARI) Kabupaten Ketapang yang telah memberikan kesempatan bagi peneliti untuk melangsungkan penelitian dan memperoleh data dan memberikan dukungan serta mengarahkan peneliti dalam proses pengambilan data.

DAFTAR PUSTAKA

Almant J. 1974. Observational Study Of Behavior : Sampling Methods. Alle laboratory of animal behavior. University of Chicago: Illinois, USA.

Atkinson, M.W. 1997. New Perspective on Wildlife Rehabilitation. Z00 biology.

Hermawan N, Pribadi T, Silvianingsih AY. 2018. Perilaku Harian Anak Orangutan (Pongo Pygmaeus Wrumbii, Tiedmann 1808) di Pusat Rehabilitasi Protect Our Borneo Sei Gohong, Palangka Raya. Conference Paper. Fakultas Pertanian dan Kehutanan Universitas Muhammadiya Palangkaraya.

Kaplan, G dan Rogers, L. J. 2002. Pattern of Gazing in Orangutans (Pongo Pygmaeus). Intern. J. Primatol

Kuncoro, 2004. Aktivitas Harian Pongo Pygmaeus Rehabilitant di Hutan Lindung Pegunungan Meratu KalTim. Skripsi Universitas Udayana.

Mawarda, P. A. 2010. Perilaku Harian Orangutan (Pongo Pygmaues) Dalam Konservasi Ex situ di Kebun Binatang Surabaya. Jurnal 
Biologi. Jurusan Biologi, Fakultas Matematika Ilmu Pengetahuan Alam, Institut Teknologi Sepuluh Nopember.

Purnawan H, Prayogo H, Anwari MS. 2016. Perilaku Harian Orangutan (Pongo Pygmaeus) Di Yiari Ketapang, Kalimantan Barat. Jurnal Hutan Lestari 4 (4): 628637.

Rijksen, H. D. 1978. A Field Study on Sumatra Orang Utans
(Pottgopygri aeusa belii Lesson, 1827). Ecology, Behavior and Conservation. $\mathrm{H}$ Veenman \& Zonen B.V. Wageningen.

Suhandi AP, Yoza D, Arlita T. 2015. Perilaku Harian Orangutan (Pongo Pygmaeus Linnaeus) dalam Konservasi Ex-Situ di Kebun Binatang Kasang Kulim Kecamatan Siak Hulu Kabupaten Kampar Riau. Jom faperta 2 (1): 1-14. 